\title{
MUJERES EN LAS “GUERRILlaS" PERUANAS DE FINALES DEL SIGLO XX
}

\author{
Marta Romero Delgado y Concepción Fernández Villanueva \\ Universidad Complutense de Madrid \\ martaromerodelgado@mail.com - cfvillanueva@cps.ucm.es
}

Recibido: 28-02-2011

Aceptado: 26-04-2011

\section{Resumen}

En las dos últimas décadas del pasado siglo se formaron y desaparecieron movimientos armados en la sociedad peruana, popularmente llamados "guerrillas". Dichos grupos se enfrentaron al Estado provocando una fuerte oleada de violencia política. La participación femenina en todo el proceso fue muy amplia e inesperada. Tras una investigación cualitativa en la que se entrevistó a mujeres de los dos grupos armados más importantes, Partido Comunista del Perú-Sendero Luminoso (PCP-SL) y Movimiento Revolucionario Tupac Amaru (MRTA), presentamos las razones sociales e identitarias que condujeron a las mujeres a su implicación en esta expresión de violencia política, así como la problemática de fractura y reconstrucción identitaria que se vieron obligadas a realizar y la evaluación de sus experiencias.

Palabras clave: Mujeres, movimientos guerrilleros, violencia, identidad, evaluación.

\begin{abstract}
In the last two decades of the last century there have been formed and eliminated armed movements in the Peruvian society, popularly called guerrillas. Those groups confronted the State causing waves of political violence. In these groups, the women's participation was very wide and unexpected. After a qualitative research based on interviews of women from the most important armed groups (Shining Path and Tupac Amaru Revolutionary Movement), we present the identity and social factors that led to their involvement in this expression of political violence, as well as the problematic of identity fracture and reconstruction they needed to carry out, and the evaluation of their experiences.
\end{abstract}

Key Words: Women, guerrilla movements, violence, identity, evaluation. 


\section{Presencia y representación social de las mujeres en los grupos alzados en armas}

Durante todo el siglo XX en la sociedad peruana existieron poblaciones históricamente discriminadas, así como grandes desigualdades por cuestiones sociales, de género o etnia. La discriminación y la desigualdad son el germen de la violencia en el final del siglo. En 1980 el Partido Comunista del Perú-Sendero Luminoso (PCP-SL) inicia una "Guerra Popular" contra el Estado peruano, tras reconocer a Abimael Guzmán (Presidente Gonzalo) como “jefe del partido y la revolución”. Más tarde, en 1984, se suma a la lucha contra el estado el Movimiento Revolucionario Tupac Amaru (MRTA), iniciándose así un conflicto armado que dejará un alto número de pérdidas humanas y materiales y que se prolongará hasta el 2000. Estos dos grupos alzados en armas, llamados popularmente "guerrillas", integraron en sus filas a un alto porcentaje de mujeres, lo cual sorprendió bastante a la sociedad peruana y plantea importantes cuestiones sobre las razones de la presencia de las mujeres en la violencia política.

En 2001 se crea la Comisión de la Verdad y Reconciliación (CVR) para elaborar un informe que plantee las causas de la violencia de dicha época, así como los daños infringidos y su coste a todos los niveles. La CVR (2003) ha identificado patrones de crímenes y violaciones de los derechos humanos perpetrados por las organizaciones subversivas, y por las del Estado, como parte de sus respectivas estrategias: desapariciones forzadas; ejecuciones arbitrarias; asesinatos y masacres; torturas y tratos crueles, inhumanos o degradantes; violencia sexual; violación del proceso judicial debido; secuestros y tomas de rehenes; y violación de derechos colectivos. La violencia ejercida por los dos frentes derivó en la desintegración y la polarización de las comunidades (Pedersen, 1999). Estos procesos afectaron a las mujeres no solo como víctimas, sino también como agentes, y son la urdimbre en la que se asienta su participación en los conflictos armados.

El Informe final de la CVR afirma que un $40 \%$ de los militantes de Sendero Luminoso eran mujeres, al igual que el 50\% de sus cuadros. En el Comité Central del Partido ocho de su diecinueve miembros eran mujeres (Jiménez, 2000).Varias investigaciones, realizadas entre 2000 y 2010, recogen la relevancia de la participación femenina así como las razones estructurales y de identidad que la explican. Narda Henríquez (2006) señala las armas como promesa de emancipación; Isabel Coral (1999) explica que si existieron tantas participantes en el grupo armado fue debido a las expectativas y disposición de las mujeres para acceder a nuevos espacios de 
participación, más que a la sensibilidad e incorporación de los intereses de género en el proyecto senderista.

Según Vega-Centeno (2000), el PCP-SL desplegó su estrategia de captación femenina teniendo en cuenta la situación previa de tremenda marginación de la mujer peruana: discriminada por el Estado y la sociedad, recluida en el ámbito privado del hogar, controlada por las leyes patriarcales y confirmada en este papel por la religión, sin opción alguna de participación en la vida social o política. Laura Balbuena, (2007) arguye que el PCP-SL, al igual que otros grupos armados, tiene diversas razones para incorporar mujeres en sus filas. Razones como la ventaja táctica (ellas levantan menos sospechas que los varones), el aumento del número de combatientes, mayor publicidad (ya que la prensa le da más cobertura a las acciones violentas femeninas que a las realizadas por hombres), y finalmente, el efecto psicológico, la sensación de inseguridad y vulnerabilidad de la sociedad en su conjunto.

Dentro del PCP-SL se creó el Movimiento Femenino Popular (MFP) dedicado a la politización de las mujeres del Partido. Este hecho sin duda contribuyó a engrosar la presencia de mujeres en sus filas, ya que en la otra organización estudiada (el MRTA) en la que no existía algo similar, el porcentaje de mujeres es menor. Que las mujeres tuvieran cargos políticos de primer nivel jerárquico, en el PCP-SL, supuso un cambio sobre la anterior participación femenina en los partidos tradicionales, tanto de derecha como de izquierda.

La ideología socialista y comunista que está en la base de estas organizaciones dedicaba importante atención a la liberación femenina. Tanto el PCP-SL como el MRTA se identifican ideológicamente con Marx, Lenin y José Carlos Mariátegui, los cuales hacen claras referencias al "problema de la mujer". Según Mariátegui existen tres tipos de feminismo -el burgués, el pequeño burgués y el proletario- y para llevar a cabo la revolución es necesario abrazar al proletariado femenino con el propósito de educar a las futuras militantes e incorporarlas en la lucha de clase. Además, el PCP-SL también toma de Mao la premisa de que los hombres no pueden ser libres mientras las mujeres no sean liberadas (Lázaro, 1998).

A principios de los años 70, Catalina Adrianzen escribió el manuscrito "Marxismo, Mariátegui y el Movimiento Femenino", que sentaba las bases para la constitución del Movimiento Femenino Popular (MFP) del PCP-SL. Este escrito importante para las mujeres del PCP-SL- define la identidad de "mujer comunista". Sin embargo, sorprende que ni en dicha organización ni en el MRTA exista afinidad alguna con el feminismo ni con el enfoque de género. Estas premisas ideológicas explican el verdadero estado de la igualdad de género en el interior de sus organizaciones o 
partidos. En los testimonios se puede observar cómo, al estar ausente del ideario revolucionario todo análisis en torno a la desigualdad genérica, se les exigía a las mujeres comportamientos iguales a los de los hombres en una situación de desigualdad real, lo que originó las fracturas identitarias que comentamos más adelante.

Las formas de militancia femenina eran muy diversas en estos grupos. En el PCP-SL existían, por un lado, los cuadros comprometidos con la propuesta ideológica y con la guerra popular, tanto columna como fuerza principal o de base, o trabajando en Socorro Popular, que se caracterizan por la adhesión incuestionable al partido y al líder. Por otro lado están los cuadros emergentes -de segunda línea, pero en proceso de preparación ideológica- donde se combina la inquietud social con la experiencia propia de injusticia y marginación. En tercer lugar figuran las simpatizantes, que se incorporan al conflicto porque sienten que el PCP-SL es una alternativa de poder al que de otra manera no accederían. Estas últimas sienten una menor convicción ideológica y menor comprensión de la guerra. Finalmente, las reclutadas por la fuerza; de ellas, algunas asumen un comportamiento adaptativo mientras que otras muestran cierta alienación como manera de sobrevivir (CVR, 2003).

A pesar de los insistentes datos que resaltan la presencia femenina en los movimientos guerrilleros, los documentos más oficiales, y principalmente los medios de comunicación, siguen presentando una imagen de falta de agencia, invisibilización o estigmatización. El libro que más se ha difundido respecto a las mujeres del PCP-SL ha sido "Grabado en piedra. Las mujeres de Sendero Luminoso", de Robin Kirk (1993), donde una vez más se reproducen los estereotipos de género. Al hablar de una joven que se enroló por decisión propia en el PCP-SL, afirma Kirk «También yo tengo mis opiniones al respecto. Mientras observo a Betty, me pregunto: ¿cómo pudieron engañarla? ¿No son las mujeres lo suficientemente listas y despiertas como para descartar la guerra? Pienso en las mujeres como forjadoras de la paz, como seres entregados a la crianza. Ciertamente, figuras políticas como Margaret Thatcher pueden hacer el juego de la guerra. Pero, ¿entregarse a lo que Sendero Luminoso llama su “máquina de matar"? Cuando planteo el tema mis amigas feministas me miran con desconfianza. Ellas creen que no es cierto que las mujeres se unan a Sendero Luminoso, una guerrilla embustera que solía aparentar más poder del que tenía. “¿Mujeres?”, dicen. "Sólo unas cuantas locas" (Kirk, 1993:16-17).

Incluso a lo largo del Informe Final de la Comisión de la Verdad y Reconciliación, la idea que prevalece sobre las mujeres es la de víctimas de un conflicto en el que ellas no tomaron parte activa, sino que se hallaban en un "fuego cruzado" donde, 
“[...] eran demandadas por los grupos subversivos o por las Fuerzas contrasubversivas para cocinarles, atender enfermos y dar alojamiento. No tenían opciones y debían obedecer sin protestar, pues su vida y la de sus familiares estaban en peligro. La mujer no era escuchada; sus razones no eran consideradas por unos ni por otros. Esta situación de invisibilidad y marginación, si bien existió previamente, se agravaba por el conflicto interno. Las mujeres, cuyas voces no han sido usualmente consideradas relevantes ni autorizadas, fueron en este contexto nuevamente silenciadas" (CVR, 2003:70.Tomo VIII).

Estos fragmentos son un claro ejemplo de que la violencia simbólica que opera sobre las mujeres en general (Bourdieu, 2007), está presente también a la hora de analizar los conflictos armados y las guerras, y tiene como consecuencia no ver más allá de los roles tradicionales de género, y definir su participación e importancia como "periférica".

Pero los medios de comunicación presentan una imagen mucho más polarizada y distorsionada que estos informes. Ricardo Caro (2006) escudriña las referencias públicas acerca de dos jóvenes senderistas, Edith Lagos y Carlotta Tello, sobre las que recayó un grave estigma social, por haber causado lo que el autor denominó “ofensa patriarcal" al transgredir los roles tradicionales La prensa retrataba a las mujeres de Sendero como más salvajes que los hombres, frías, sin sentimientos, sedientas de sangre y de sexo, como desnaturalizándolas; eran la "anti-mujer", la mujer masculinizada (Kirk, 1993). De hecho, el estereotipo femenino tradicional responde a todo lo contrario: la mujer como portadora de vida, con instinto maternal, pacificadora y pacífica por excelencia. Al transgredir dicho estereotipo universal las mujeres se llevan la peor parte, más que sus propios compañeros del PCP-SL.

"Para los diarios, sólo hay dos tipos de mujer senderista: la autómata asexuada, fría como el metal de un instrumento bélico; o la diosa de la lujuria, una ninfómana sedienta de sangre. Abundan los comentarios sobre su crueldad, belleza y apetito sexual" (CVR, 2003:17.Tomo VIII).

La sociedad peruana, no dejaba de asombrarse ante la noticia de la gran cantidad de mujeres que se enrolaban al "Ejército del Pueblo" y portaban armas para "cambiar el viejo orden social". Para unos era inconcebible, para otros, propio de la tradición autoritaria por la que pasaba el país. Algunos decían que eran jóvenes engañadas o atraídas porque sus novios eran del Partido; para muchos, era algo "simplemente repugnante". Lo que está claro es que a nadie dejaba indiferente. Esta imagen se refleja y se refuerza desde algunas instancias del poder, recorriendo así el camino de ida y vuelta poder/medios de comunicación que describe Bourdieu (1998). 
Un manual de la policía con fecha de 1990, describe a las mujeres senderistas de esta forma:

“[...] son más determinadas y peligrosas que los hombres, tienen conductas absolutistas, y se consideran capaces de desempeñar cualquier misión, poseen la dicotomía de la debilidad y la dureza, son indulgentes, sumamente severas... explotan y manipulan al prójimo, son impulsivas y arriesgadas" (Kirk, 1993:18).

Es así como surge un imaginario colectivo donde toma cuerpo la norma senderista-mujer-perversa, como si existiera una crueldad específicamente femenina, o en palabras de Vega-Centeno "como si el terrorismo y lo sanguinario fueran de una especial y exclusiva perversión, afín a la manera de ser femenina" (Vega-Centeno, 2000:212).

\section{Trayectorias e identidades de las mujeres "guerrilleras"}

El presente trabajo nace con el deseo de comprender la significación de la guerra para las mujeres en el conflicto armado interno en Perú. A pesar de las investigaciones que explican diversas razones estructurales, hay curiosidad por conocer las dimensiones más próximas a la identidad y los motivos personales que las mujeres aducen. La propia Vega Centeno (2000) señala la dificultad de reconstruir las características femeninas que reconoce y utiliza el PCP-SL en sus militantes mujeres, y concluye que las razones de seguridad y el hermetismo del grupo clandestino impiden por el momento la reconstrucción del imaginario femenino senderista.

Nos preguntamos, tal y como lo hicieron las investigadoras Blair y Londoño (2003) con mujeres combatientes de Colombia, ¿qué buscan las mujeres participando en la guerra? ¿Qué las hace renunciar a su vida "normal" y en ocasiones a una serie de situaciones y experiencias que definen el "ser mujer" en esta sociedad? ¿Cómo han vivido la guerra? ¿Cómo afrontan en la actualidad su vida, después de largas condenas o permaneciendo aún en la cárcel? Se trata de interrogantes dirigidos a conocer cómo se inserta la lucha armada en la identidad psicosocial de las mujeres. Para responder a estas cuestiones, hemos recurrido a su memoria y su reflexión captadas a través de su palabra, con el fin de indagar en el impacto que supuso para ellas el conflicto que marcaría sus vidas en lo personal, lo familiar, lo político y lo social, transformando así su identidad. 
El universo de estudio lo componen las mujeres que de alguna manera se implicaron en los grupos armados, bien por su incorporación a los mismos antes o durante el conflicto, o bien por entrar en contacto con ellos ya en la cárcel. La recogida de información se realizó mediante varias técnicas cualitativas. Después del trabajo documental, de varias visitas a las organizaciones guerrilleras, ONGs, comisionados de la Comisión de la Verdad y La Reconciliación, asociaciones de familiares y afectados/as por la violencia y a profesores/as, se realizó un primer contacto con mujeres del PCPSL y del MRTA encarceladas. Se realizaron varias reuniones de grupo en las que se comentaba la experiencia en la guerra y en la cárcel. Más tarde a través de entrevistas en profundidad con 6 integrantes del PCP-SL y 2 del MRTA. Un segundo bloque de información procede de mujeres que no estaban en la cárcel y que habían pertenecido al movimiento guerrillero Sendero Luminoso. Las mujeres entrevistadas tienen una edad media de 50 años (la más joven rondará los 40 años y la más mayor, los 65 años). Las mujeres entrevistadas fueron importantes en el movimiento y sus hechos realmente relevantes, a juzgar por la gravedad de las condenas que les fueron impuestas. Algunas incluso había sido condenadas a cadena perpetua; otras, hasta a 18 años de cárcel. Las que no estaban en prisión fueron asimismo muy representativas en los grupos a los que pertenecieron. El núcleo de las preguntas tratadas se refirió a las razones de la entrada en la organización, la experiencia dentro de ella y la experiencia posterior, tanto dentro como fuera de la prisión. La información de las entrevistas fue grabada y transcrita. Para codificarla y organizarla se ha utilizado el Atlas.Ti.

La información obtenida se ha agrupado en una serie de bloques temáticos y dentro de cada uno de ellos hemos identificado los repertorios interpretativos que confieren significación a la experiencia. Los bloques temáticos son: la entrada en los movimientos, la participación en las acciones guerrilleras y la transformación de la identidad, la experiencia posterior en la prisión y la evaluación de las acciones realizadas.

El concepto de "identidad posicional" de Alcoff (1988), como identidad sensible a las modificaciones contextuales y dependiente del contexto histórico concreto adquiere aquí plena significación como principal explicación general de la entrada de las mujeres en los grupos peruanos alzados en armas. Al preguntarnos cómo se va fraguando la identidad de estas mujeres para saber cómo posteriormente se insertan con "naturalidad" en los grupos armados, observamos que aparecen repetidamente referencias y guiños al pasado que las marcan vital y políticamente.

Por aquel entonces, en Latinoamérica se sucedieron una serie de movimientos armados inspirados en la Revolución Cubana (1959), a los cuales los países contestaron 
con golpes militares y dictaduras represivas. Estas influencias ideológicas y revolucionarias de los países vecinos también llegaron a Perú. Las acciones guerrilleras de 1962, 1963 y 1965 (esta última por Movimiento de Izquierda Revolucionaria, MIR y el Ejército de Liberación Nacional, ELN) conmocionaron la institucionalidad política, más aún al reclamar transformaciones que el sentimiento popular reconocía como necesarias.

Estas revueltas y cambios sociales van marcando la identidad de muchos/as peruanos/as y, en concreto, de las mujeres de nuestra investigación, que se tornan cada vez más conscientes de su contexto histórico, de las revueltas en otros lugares del mundo y especialmente en Latinoamérica. Las organizaciones dentro de las cuales se insertan las entrevistadas tienen un programa político definido, de eso no cabe duda, pero lo que nos interesa escudriñar es qué les hace optar por esa y no otra opción política. ¿Por qué tienen la convicción de que es ese el camino a seguir a cualquier precio? Al plantearnos estas cuestiones, tenemos que tener en cuenta el concepto de cultura política de cada persona, es decir, el conjunto de creencias y valores compartidos, y el rol de las actividades políticas en la conservación y la orientación de la cohesión social (Lagroye, 1993). La cultura política es generada a través de la socialización política adulta o secundaria cuyos principales agentes son las instituciones educativas, asociaciones y partidos políticos y ser donde aprenden a hacer propios los principios, normas, valores y modelos de comportamiento vigentes para la vida política de la sociedad, sea la actual o la deseada e imaginada. Las experiencias socializadoras más variadas se sedimentan en formas más o menos duraderas de ver, sentir y actuar y esos productos del pasado incorporados por estas mujeres determinan en parte sus acciones y reacciones (Lahire, 2007). El proceso es tan fuerte que en ocasiones llega a ser una verdadera "re-socialización” (Arnoletto, 2007).

La mayoría de las entrevistadas, especialmente aquellas procedentes de zonas urbanas, distinguen entre la socialización en la familia y en la universidad, dando mucha importancia a esta última. Por otra parte, en los testimonios recogidos se aprecia como la cultura política de las entrevistadas se va forjando poco a poco a partir de referentes familiares, al identificarse con hermanos mayores, padres, madres; pero también por el contexto socio-político que se vivía entonces en Perú: el auge del movimiento vecinal, las ocupaciones de tierras, las luchas por la luz y el agua, van forjando su "conciencia política". Los partidos políticos y sus declaraciones ideológicas definen los objetivos a alcanzar, las líneas concretas de actuación en el contexto peruano. 
"En el 80, participé con Izquierda Unida en las elecciones. Ahí es cuando sale Sendero Luminoso. [...] A los 16 años ingreso en la UNI (Universidad Nacional de Ingeniería) para estudiar Ingeniería Química. Yo seguía buscando lo que más me convenciera políticamente, los de Izquierda Unida me parecían unos reformistas, pero tampoco me convencía lo de Sendero. En la UNI tengo contacto con el guevarismo, además de con el maoísmo. Me identifico con la revolución latinoamericana, con la Patria Grande y con Mariategui, era el año 83" (Testimonio 5, MRTA).

Prácticamente todas las mujeres entrevistadas, tanto del PCP-SL como del MRTA, especialmente si pertenecen a zonas urbanas, señalan como principal motivo de su incorporación la "sensibilidad social". En su discurso, la sociedad dividida en clases genera desigualdades sociales y económicas, por lo que existen dominantes que oprimen a dominados/as. Entienden que a través de su inserción en la Organización, serán la vanguardia del proletariado, que asumiendo su "deber histórico", liberará al pueblo de su opresión. Sería entonces la combinación de factores lo que las impulsa a la acción: aparecen claros los motivos racional-políticos, así como las motivaciones subjetivas (Ibarra, 2007).

Para algunas mujeres resulta clave en su historia vital el hecho de que alguno de los familiares ya estuviera involucrado en el conflicto. En ese caso, sienten que quedan inmersas en el conflicto "lo quieran o no". Es decir, dan una explicación "naturalizadora" ya que la opción política parece determinada por las obligaciones familiares.

Un grupo de ellas, principalmente las de zonas rurales, consideran su incorporación a un grupo armado casual, debido a que "no tienen más remedio", resulta casi una imposición, a pesar del miedo. Más que nunca, hay que tener en cuenta el contexto interpersonal en el que se sitúa la acción. Entorno de presión social, polarización, amenaza o condiciones de precariedad que obliga en cierto modo al ingreso en los movimientos armados.

Otras, identifican una influencia familiar positiva, más indirecta, relacionada con "sensibilidades" y con "dar a los demás". En la formación de la identidad de estas, sobre todo si son de procedencia rural, se hace evidente la influencia religiosa, pero no tanto como una elaboración específicamente doctrinaria, sino como una cierta resignación por las cosas que les suceden, como si fuera el "destino divino" donde está todo marcado y hay que acatarlo. Este influjo marcará su vida y, claro está, la manera de ser de hombres y mujeres: resulta impensable cualquier variación, ya sea el destino de insertarse en los grupos armados o el de casarse y tener hijos/as cuándo sea oportuno.

Previo al ingreso en la organización armada, muchas de las entrevistadas, habían tenido otras experiencias políticas breves, la mayoría con la "izquierda legal", 
formando parte también de su socialización política. Hablan de las diferencias de esos partidos respecto a los grupos armados a los que pertenecen, así como de su incesante búsqueda porque los partidos "no les convencían".

Frecuentemente se habla de una "mística" peculiar universitaria, especialmente en las universidades públicas, donde se podían ver imágenes, estatuas y símbolos representativos de pensadores del momento, normalmente de izquierdas. Incluso expresan que la perciben como si fuera una "micro-sociedad" bien diferenciada respecto del resto que estaba fuera de los muros de la universidad. Todo esto se atribuye al sentimiento y la voluntad de los jóvenes por "transformar la realidad".

\section{Fracturas, rupturas y reconstrucciones de identidad de las mujeres en los grupos armados}

Las mujeres de los grupos alzados en armas se enfrentan con dos desafíos: en primer lugar, mantener su identidad femenina en un mundo en el que se impone una acción al menos discordante con lo que se espera de ellas. En segundo lugar, reconstruir la ruptura con los roles familiares y maternales internalizados en el proceso de socialización.

La acción en el interior de las organizaciones planteó importantes transformaciones de comportamiento e identidad a las mujeres, dada la contradicción ya mencionada entre el discurso de "liberación de la mujer" que se defendía en los partidos políticos a los que pertenecían las organizaciones armadas y la estructura masculinizada de los grupos concretos y sus normas. Efectivamente los grupos armados no sentían muchas simpatías por las actitudes feministas; tampoco las propias mujeres eran feministas en el sentido propio de la palabra.

Según la mayoría de las entrevistadas, especialmente las del PCP-SL el feminismo es una "teoría burguesa", y las feministas "dicen y hacen lo que interesa al poder". Piensan que "las mujeres somos la mitad que sostiene el cielo, y aunque siendo mujer hay un planteamiento de igualdad con el hombre, el problema no es de sexo ni de género, es de clase":

\footnotetext{
"Ahora en las universidades se habla mucho de género, pero eso es para no hablar de marxismo, como antes. El género ha suplantado al marxismo, eso es lo que conviene al imperialismo. [...] Nosotras estamos por la emancipación de la mujer y contra la liberación de la mujer, porque sólo se puede luchar con el proletariado, porque hay que
} 
luchar. Este es uno de los objetivos, ha habido causas que desataron la lucha. [...] Estoy convencida de que habría una real libertad (para las mujeres) con una Revolución Cultural, como dice Mao" (Testimonio 2, PCP-SL).

En consecuencia en el seno de los grupos armados, las mujeres o bien se adaptan a las normas masculinas y ascienden cumpliéndolas por todos los medios, o abandonan la militancia ante la imposibilidad de cumplir con esos niveles de exigencia, Es menos frecuente que los acepten y adopten a la vez una actitud crítica al respecto, como también señalan Vázquez, Ibáñez y Murguialday (1996). Las mujeres críticas tanto del PCP-SL como del MRTA parecen ser una minoría. Una entrevistada que llegó a ser alto mando político-militar del MRTA y que actualmente sigue en la cárcel con cadena perpetua, realiza un interesante balance retrospectivo acerca de la existencia de la igualdad. Considera que en su Organización se las discriminó por ser mujer, llegando a reproducir los mismos esquemas sexistas del resto de la sociedad. Afirma que, en ocasiones, debieron adoptar "actitudes masculinas" para "poder ser valorada igual que un hombre", pero siempre combinándolo con rasgos propios de la identidad femenina tradicional, en definitiva, "manteniendo los valores de la mujer nueva".

No menos importante es la fractura y necesidad de reconstrucción de los roles de las integrantes de los grupos armados con respecto a los vínculos anteriores, familiares y de comunidad social pequeña. La familia podía llegar a comprender que ingresaran en algún partido de la "izquierda legal”, pero no era fácil aceptar la decisión de las hijas de ingresar en grupos armados En consecuencia, la decisión conlleva en muchas ocasiones, hacer frente al rechazo de su familia y de su medio social. Las reacciones familiares predominantes eran de rechazo, asombro, temor y miedo por lo que pudiera sucederle a su hija, agudizado por el hecho de ser mujeres.

"Cuando yo les comunico esto a mis padres, que yo había decidido... estar con los compañeros, en mi casa les chocó bastante, ¿no?, a mi papá y a mi mamá. Tanto que ellos dijeron..., ellos habían sentido que habían perdido una hija, me imagino porqué... Y quisieron que esa pérdida sea más rápida, antes que sea así, pues, de a poquito, y que, me dijeron que yo, ya no debía regresar a la casa. Me botaron, me echaron" (Testimonio 7, PCP-SL).

En ocasiones, la situación de ingresar en el grupo armado implica la polarización de intereses, una fractura identitaria que puede obligarlas a tomar decisiones dolorosas. Se puede dar el caso de que la familia necesite el cuidado y la atención de la mujer, mientras que ella se sienta impulsada por los hechos a ser activa fuera de casa. 
"Muchas mujeres tienen grandes reservas de energía emocional y física para cumplir con los dos papeles; a veces tienen que elegir entre los dos y enfrentarse a sentimientos de culpabilidad de alguna clase" (Panos Institute, 1995:22).

En los testimonios se aprecia de nuevo que la fuerza para tomar las decisiones se la dará la doctrina ideológica y, sumamente convencidas deciden insertarse en sus organizaciones sin dudar de su victoria.

\begin{abstract}
"A medida que más me comprometía con la lucha revolucionaria, el equilibrio se fue resquebrajando hasta romperse. [...] Di mil vueltas al problema, no soy de tener cargos de conciencia, más bien analizo, sopeso varios aspectos. Eso me tomó bastante tiempo. Opté por la ruptura definitiva, me rebelé contra el papel que esta sociedad le impone a la mujer: tener y educar a los hijos y trabajar para aportar a la producción social que sostiene un sistema injusto. Me entregué a la brega por transformar tal sociedad. Me até el corazón con mis tripas y salí sin voltear atrás a riesgo de convertirme en sal. Dije para mis adentros -cuando tomemos el poder volveré a mostrarles el mundo nuevo que construiremos los comunistas y el pueblo nuevo" (Testimonio 13, PCP-SL).
\end{abstract}

La culpa y el miedo marcan la experiencia de la separación de la familia, no solo por romper con los roles tradicionales sino también por lo que le suceda a sus familiares, saben que estos/as tendrán que hacer frente a sospechas, detenciones y persecución. La culpa, entonces, es vivida como una relación de causa-efecto, atribuyéndose ellas mismas la causa de sufrimiento de su familia. Para muchas de nuestras entrevistadas, así como para las guerrilleras entrevistadas por otras investigadoras, "la preocupación por el riesgo personal que suponía cada acción no era nada comparado con el miedo cotidiano a ser descubierta y a que la represión cayera sobre sus familias" (Vázquez, Ibáñez y Murguialday, 1996:131). Estos sentimientos colocan a "las mujeres que recurren a la violencia física en una situación de particular vulnerabilidad emocional, en cuanto no sólo se enfrentarían a un juicio más severo sobre sus acciones de violencia por parte de otros, sino a una mayor carga de culpabilidad proveniente de su propio enjuiciamiento sobre sus actos violentos" (Blair y Londoño, 2003:45).

Pero si hay un componente en su subjetividad que ha permanecido a sus variaciones ha sido la dimensión maternal, hasta el punto de poder hablar de una "subjetividad maternalista" (Luna, 2002). En bastantes entrevistas, se afirma que "toda mujer desea o quiere tener hijos".

\footnotetext{
"Yo no sé cómo será en tu caso, pero pienso que la mayoría de mujeres sí deseamos tener hijos, ¿no? Por lo menos, (risas), tener familia, tener niños. Es parte de realizarse como mujer, ¿no? Y... es una situación bastante dolorosa, pienso... el hecho de que no se pueda realizar" (Testimonio 7, PCP-SL).
} 
La maternidad es el proceso que más en duda pone la identidad guerrillera. Como refleja el testimonio de una mujer, las primeras horas después de nacer su hija, al mirarla, al sentirla, todo ese cúmulo de sentimientos hicieron que llegara a poner en duda su identidad como combatiente.

\begin{abstract}
"Me traen a mi hija y la veo, la criatura más hermosa del mundo, sonrosada, con unas inmensas pestañas, como las de su padre, gordita y sanita. Todo en mí cambió, y cuando ella succionó mi pecho, me fundí a ella en una sola, lloré de emoción, no sé como expresar en palabras este sentimiento que nació en mí, me sentí transformada, el tenerla en mis brazos me daba otra dimensión, era mi criatura, era mi bebé, era un pedazo de mí que cobraba vida, y yo acariciándola, protegiéndola, dándole alimento de mi cuerpo. Sentí surgir en mí ese sentimiento tan excepcional que da el ser madre. [...] Yo había quedado con el padre de mi hija que debía entregarla a su hermana porque no había condiciones para cuidarla en el penal [...] Pero al ver, tocar, dar de lactar, cambiarla, atender a mi hija, mi perspectiva cambió. Yo ya no quería desprenderme de ella, yo quería vivir con ella, yo quería darle todo mi amor y protección que sólo una madre puede dar a su hija. [...] Separarme de mi hija... debía aceptarlo... No ser su madre del día a día..., no poder darle todo este torrente de amor que ella me inspira... ¡Cómo me llené de impotencia al estar presa!... Pero qué difícil es decirle al corazón las razones de la razón... Esta es la herida del alma que me marcó y que se abre por no poder estar junto a mi hija" (Testimonio 5, MRTA).
\end{abstract}

Algo muy diferente ocurre con las mujeres que no son madres. Estas suelen ser tajantes, aducen que no tienen hijos/as debido a que "realizaron la elección racionalmente y ganó la opción de la lucha". "No tengo hijos, fue mi decisión. Yo decidí entregarme a la Revolución y no me pesa" (Testimonio 2, PCP-SL). A pesar de ello, el tema de la maternidad está presente en el relato constantemente. La situación de las mujeres que eran madres en las zonas rurales era particularmente difícil, debido a las condiciones de clandestinidad y a la escasez de recursos sanitarios, entre otras cosas. Las condiciones de vida de los/as combatientes en los campamentos de la selva o la sierra de Perú durante el conflicto eran especialmente duras; tanto hombres como mujeres tenían que hacer frente a multitud de cambios, desde la alimentación y el vestuario hasta la manera de relacionarse personalmente. Algunas mujeres nos han relatado que mientras estaban inmersas en labores de combate durante el conflicto, la ya de por sí situación excepcional, se incrementa al tener que parir en condiciones “anormales". En el caso de muchas de las mujeres, especialmente las urbanas, aunque tuvieran un deseo explícito de ser madres no pudieron porque, en el momento de su detención, eran jóvenes y posteriormente tienen que afrontar largos años de condena o incluso continúan en la cárcel y, como dicen ellas, "ya no están en edad fértil”, lo que les causa una "sensación de frustración". Esta postergación o retraso de la maternidad suele provocarles gran dolor. 
En todo caso, la mayor preocupación era asegurarse el cuidado de sus hijos/as, por lo que si las mujeres se quedaban embarazadas durante el conflicto, mientras estaban en clandestinidad, eran conscientes de que debían criarlos sus familiares o alguien de su confianza. Ello implicaba separar la función biológica (tener hijas/os) de la función social (crianza). Una manera efectiva que tuvieron los partidos y organizaciones para solventar esta separación fue, una vez más, apelando a la identidad revolucionaria, es decir, incorporando a la "doctrina revolucionaria" el concepto de "maternidad extendida", donde su responsabilidad como madres no sólo está con sus propios hijos/as, sino "con todos los niños del mundo", sustituyendo el ejercicio de una maternidad individual por una maternidad colectiva. Los sentimientos no podían individualizarse, debían ser colectivos, de lo contrario serían catalogados como sentimientos burgueses. La colectividad de los sentimientos y responsabilidades les dará fuerzas a la hora de tener que dejar su familia e hijos/as por la "causa revolucionaria". El miedo de que los hijos pequeños sean “objetivos fáciles" para el Gobierno y el Ejército, que intentarán descubrir a sus madres, se añade a la preocupación por su crianza y por la seguridad de sus cuidadores. Es frecuente que hagan referencias al dolor ocasionado por tener que dejar a sus hijos/as desde temprana edad. Como dicen, "será una herida abierta para toda la vida", y de nuevo se impone en sus relatos la culpa. De hecho, para muchas madres, el sentimiento de culpabilidad ocasionado por el mandato de dejar a sus hijos/as, se agravaba debido al posterior “juicio social” más severo con estas mujeres que con sus compañeros varones.

Ante tal situación, las mujeres intentan reconciliarse consigo mismas, argumentando que no tenían otra opción y que intentaron conseguir las mejores condiciones que podían ofrecerle a sus hijos/as en ese momento. Son evidentes las dificultades que estas madres tendrán para establecer vínculos afectivos tras largas condenas; en no pocos relatos aparece el temor por el futuro de la relación. Una mujer que estuvo doce años en prisión, nos cuenta en detalle cómo afronta, en sus palabras, las "cosas de madre", comprende que su hija establezca los vínculos más estrechos con quienes ha convivido el día a día, resignándose a que el lugar que ocupe ella en la vida de su hija sea "como una amiga y no como una madre" (Testimonio 9, PCP-SL).

Los familiares juegan un papel muy importante debido a que, si bien en ocasiones, los/as hijos/as no les reconocen, se convierten en la única esperanza que tienen las madres para mantener ese vínculo y esa relación viva a pesar de las dificultades. Son especialmente emotivos los relatos donde cuentan cómo sus hijos/as las reconocen después de tiempo sin verlas. En otros casos, consideran que es mejor no seguir alimentando esos lazos afectivos debido a su particular situación penitenciaria. 
Una mujer condenada a cadena perpetua, en un intento de proteger sus hijos/as y que no les resulte tan doloroso, termina por asumir la posibilidad de que nunca saldrá de la cárcel y les pide que no la visiten más.

Para saber cómo estas mujeres son capaces de afrontar estas fracturas identitarias, es importante destacar la dimensión colectiva, grupal, de los sentimientos y de la maternidad. Destacamos el importantísimo papel de las compañeras como copartícipes de la maternidad, ayudantes en la elaboración de la identidad maternal y apoyo emocional. Una mujer afirma que sus compañeras de cárcel "me ayudaron mucho, fueron como hermanas para mí".

Después de analizar todos estos relatos desgarradores, podemos concluir diciendo que al igual que sucedió con las mujeres colombianas,

"[...] la maternidad no tenía las mismas connotaciones que la paternidad. Los hombres no se enfrentaban a estos dilemas. Los hijos no constituían un impedimento para su militancia. Sin embargo, las mujeres, principalmente, las que alcanzaban altas posiciones, eran juzgadas de forma severa si decidían tenerlos. Se les criticaba que truncaran su ascenso político por una "elección sentimental". Lo que se justificaba con el argumento que los hijos apegaban a las personas, creaban lazos y generaban arraigo" (Ibarra, 2007:299).

Por lo tanto, la maternidad resultaba difícilmente compatible con la lucha, pero no la paternidad.

La participación en la guerra afecta prácticamente la totalidad del periodo vital de las mujeres ya que muchas de ellas además, tuvieron largas condenas y otras están actualmente encarceladas. Por ello el trabajo de reconstrucción de identidad debe incluir esta experiencia inevitablemente. Por otra parte muchas mujeres encarceladas no pertenecían a estos grupos, pero al existir en Perú un "estado de excepción", hubo muchas detenciones arbitrarias, especialmente a principios de los noventa. Por lo tanto, en las cárceles también se han dado muchos casos en los que las mujeres, previo al ingreso en prisión, no estaban concienciadas políticamente o, si lo estaban, no pertenecían ni al MRTA ni al PCP-SL, sino a otros grupos de la izquierda legal o asociaciones de vecinos/as. Ante estas situaciones y al tener que afrontar muchos años de prisión, habitualmente las mujeres también acabaran identificándose con alguno de los dos grupos. La cárcel funcionaba en muchos casos como "escuela política y lugar de reclutamiento" para mujeres y hombres (CVR, 2003). El comportamiento de los/as presos/as del PCP-SL en las cárceles, estudiado por Rénique (2003) muestra que su objetivo era «transformar las "mazmorras de la reacción" en "Luminosas Trincheras de Combate". Poniendo en juego su férrea voluntad de lucha, los "prisioneros de guerra" 
senderistas revertían la situación de separación de la sociedad que, supuestamente, la prisión garantizaba, para desafiar -desde su mismo patio interior- al poder constituido: una incomparable oportunidad para demostrar su ruina moral y su inviabilidad. Esa era la lógica subversiva. En ese terreno, ellos prevalecerían sobre sus captores, apelando a su superioridad ideológica y política, su valor, su disciplina y su capacidad de entrega.

La cárcel marca un punto de inflexión en sus vidas, no solamente por la tensión que supone estar encerrada en un espacio reducido sin intimidad y a merced de otras personas, sino porque dentro de las mismas se vulneraron sistemáticamente sus derechos, todo ello desde la impunidad y en connivencia con los gobiernos que se sucedían y con el resto de instituciones.

Al permanecer muchos años encarceladas, la prisión se convierte en un agente de socialización, del que en ocasiones resulta una re-socialización. En tal situación transformaron su identidad en diferentes direcciones. Algunas afianzan sus convicciones políticas surgiendo así una nueva identidad, como prisioneras o presas políticas. Incluso a la hora de hacer balance de los años en prisión, se apoyan en esa figura para autoconvencerse de "lo positivo de la cárcel". Para otras en cambio, sucede todo lo contrario, al llegar a la cárcel, consideran que ya no tiene sentido la organización, y ya no se identifican como mujer combatiente, intentan desvincularse por completo.

En todo caso, son conscientes de que deben ayudarse mutuamente, porque, como argumentan, existen personas más vulnerables. En ocasiones se daban episodios verdaderamente difíciles de afrontar de forma individual, en las que recurrían al grupo con el fin de aliviarse, disminuir la angustia y aumentar la tolerancia hacia la misma angustia. Una vez mas se resalta la dimensión grupal de la experiencia, expresada como que "el problema de cada una significa un problema de todas. Así es como a una mujer violada en la cárcel, las compañeras de celda le aconsejaron que escribiera su testimonio en una carta para más tarde leerlo a las demás, puesto que se reunían habitualmente para hablar de "sus cosas", ellas consideraban que si lo contaba se "quedaría más tranquila, porque lo sacaría de adentro" y así podría enfrentarse nuevamente al día a día carcelario después de lo sucedido pero "sin tanto dolor".

Hay que señalar la importancia a nivel identitario que conlleva la salida de la cárcel. Después de una media de quince años, el "reencuentro con la calle" actúa como un factor reconfigurador de la identidad femenina; abandonar la cárcel, instalada como un significante identitario de primer orden, para,

“[...] asumirse nuevamente como sujetos individuales y con el coste que ello significa en términos de los ajustes a realizar, representa para las mujeres excombatientes la 
posibilidad de contactarse de nuevo con su ser más femenino y recuperar aspectos de su identidad como mujeres profundamente afectadas por su experiencia de militancia armada" (Blair y Londoño, 2003:142-143).

Por lo tanto, estas mujeres tendrán que enfrentarse a una sociedad que las rechaza y estigmatiza, al mismo tiempo que intentarán restablecer los vínculos y lazos afectivos perdidos o dañados durante los años de conflicto y posteriormente de cárcel.

Como vemos, el trabajo de reconstrucción identitaria se produce continuamente, desde la entrada en la organización hasta la experiencia en la cárcel, pero alcanza una trascendencia más amplia cuando se evalúa en conjunto la trayectoria vital dedicada a la lucha y su sentido social en el contexto peruano. Sorprende la amplitud y variedad de testimonios que evalúan positivamente la trayectoria vital, tanto en relación con ellas mismas y sus familias como con la sociedad a la que pertenecen y con la historia de su país. "Sigo luchando por los pobres, entrego mi vida por construir una nueva sociedad" (Testimonio 2, PCP-SL).

En muchas ocasiones se mezcla la evaluación positiva de la lucha social con la lucha feminista por la libertad y la participación social activa:

"Voy a luchar por mi derecho como mujer libre, que nos reconozcan como presas políticas que somos. Actualmente no estamos por hacer la guerra, pero eso no implica que no sigamos luchando, porque yo voy a seguir asumiendo mi papel como mujer revolucionaria" (Testimonio 1, PCP-SL).

Es muy frecuente la ausencia de rencor y la mirada positiva al futuro, con optimismo, con la sensación de que alguien continuará una lucha en la misma dirección y que esa lucha continuara alcanzando objetivos aceptables y útiles para generaciones venideras. Esta convicción sitúa a algunas de ellas como "modelos", ejemplos a seguir.

"No miro al pasado mal, con rencor, miro al futuro. [...] Lo que he aprendido, lo que he servido, sí ha valido. No estoy de acuerdo con la sentencia que me han impuesto, pero sabía que hay costos. [...] El tiempo nos dará la razón en este milenio que es de libertad, ese camino esta hecho por millones de hombres, sí vale la pena luchar. Sobre todo cuando hay tantas compañeras que son un ejemplo a seguir y además, yo sigo viva" (Testimonio 3, PCP-SL).

Las contradicciones, las brechas de identidad y la lucha de emociones y expectativas se resuelven desde un sentido social que hace comprensible, lógica y justa la lucha armada. 


\begin{abstract}
"Antes de tomar cualquier decisión, uno siempre tenía, tiene que evaluar los pros y los contras ino? [...] Los estudios, por ejemplo, ya no los iba poder concluir, era un hecho, luego, el tener una familia, unos hijos, etc, eso era, ya, lo más remoto todavía, en esos momentos no era lo prioritario. [...] Ahora, si me preguntas en perspectiva, cómo veo eso, ¿no? desde aquí hacía atrás, yo pienso que estaba bien, lo que yo decidí, porque era lo que correspondía en ese momento, era lo necesario, porque sino hubiese sido yo, hubiesen sido otras personas, y muchas otras, ¿no? entonces, a cualquiera le hubiera tenido que suceder, en este caso, soy una de las que ha afrontado eso" (Testimonio 7, PCP-SL).
\end{abstract}

Asumen los costos, la dureza de la vida en los movimientos armados, la cárcel, el sufrimiento propio y ajeno, los muertos, la separación de la familia, con el argumento legitimatorio de la lucha por la justicia y la paz, por la evitación del dolor de otros. Lo más crudo de lo que se ha experimentado es algo lógico, incluso inevitable dentro de la opción que han tomado. En realidad, no lo ven como una opción sino como el único camino posible:

\begin{abstract}
"Yo sabía la realidad de la campaña, de la lucha. Esa es una gran lección, que la Revolución no es un camino de rosas. Es una empresa muy dura, complicada y tiene muchos costos. [...] Los costos son el sufrimiento del pueblo, los muertos y el dolor de la propia familia. [...] Hay que barrer posiciones dogmáticas para entender los cambios. Nos tildan de violentistas, dicen que amamos la violencia, pero yo amo la paz. [...]Tengo mucho optimismo, el único camino posible es el camino con violencia revolucionaria. La esencia del comunismo es luchar por la meta final, tener desinterés absoluto" (Testimonio 1, PCP-SL).
\end{abstract}

La valentía de las mujeres se presenta como evidente y lucida, valentía que llega a asumir el riesgo de la propia vida. "Pertenecí a una generación de jóvenes que estaban dispuestos a entregar lo único que tenían: La Vida y muchos lo hicieron" (Testimonio 5, MRTA).

$\mathrm{Y}$ finalmente, aunque reconozcan errores, el arrepentimiento no parece entrar en su universo cognitivo:

"En todo este tiempo, no me arrepiento de lo que hice. No tengo nada de que
arrepentirme, fue enriquecedor. Volvería a repetir porque me ha hecho crecer. [...]
Después de incorporarme al MRTA, el espíritu crítico me ayudó a preguntarme, a
escuchar. [...] Como autocrítica decir que por disciplina hemos cometido errores"
(Testimonio 6, MRTA).

En general, sienten que su vida ha estado bien empleada, aunque tengan largas condenan a sus espaldas o todavía con cadena perpetua, aseguran que no les pesa lo que hicieron porque era lo que debían hacer en ese momento por su país, por mejorar Perú. 
Sienten que ha habido un antes y un después, no solo como personas, sino como pueblo, y en eso han contribuido ellas y su lucha.

\section{Conclusión}

Frente a la invisibilización, la aplicación de los estereotipos de género a la psicología de las participantes y la desvalorización de la presencia de las mujeres en las luchas armadas conviene resaltar los factores intrínsecamente sociales y políticos que influyeron en este fenómeno. Al resaltar estos factores se acentúa la uniformidad del comportamiento femenino en las guerras con el comportamiento masculino, se desmienten algunos estereotipos de género que han sido aplicados al análisis de las mujeres en los grupos armados y ponemos a nivel de igualdad con los hombres la agencia de las mujeres implicadas en violencia política.

En primer lugar el contexto político, la cultura política y la socialización política individual y colectiva son el antecedente en ambos géneros de la implicación en los movimientos armados. En el caso que nos ocupa, las ideologías políticas que defendían la lucha por la igualdad social son el caldo de cultivo de la implicación en movimientos armados. La existencia en el seno de las organizaciones armadas en este momento de un hueco simbólico para las mujeres es una razón estructural que hace posible y facilita su presencia. Como se ha señalado, en el PCP-SL al existir un Movimiento Femenino Popular, la presencia de las mujeres fue mayor que en MRTA. La visibilidad social y la accesibilidad fueron sin duda factores influyentes como lo han sido en otras guerras más tradicionales. Es probable que muchas otras mujeres hubiesen considerado la posibilidad de enrolarse si hubiese existido un contexto de mayor accesibilidad y posibilidades.

En segundo lugar, la ideología feminista de los grupos (aunque contradictoria, ya que en la práctica no era tan evidente como en los principios teóricos), constituyó un atractivo añadido, también estructural, en línea con las demandas identitarias de las mujeres a finales del siglo XX. La idea de ser mujer revolucionaria formó sin duda parte de la identidad de las participantes como un significante muy valioso.

En tercer lugar, la polarización social, como ocurre en todas las guerras, también incidió en un pequeño porcentaje de mujeres. Algunas fueron reclutadas a la fuerza, como consecuencia de su ubicación en lugares del conflicto ocupados por el grupo o en otros en los que existía una polarización tan intensa que tuvieron que optar 
por uno u otro de los bandos enfrentados. En este caso, las razones son grupales, comunitarias y personales a la vez, es decir, quedan fuera de la cuestión de género.

El análisis de sus trayectorias, así como la verbalización de sus contradicciones con respecto a la maternidad, al rol de género en el seno de los grupos, a la preocupación por sus hijos/as y sus familiares no las refleja como crueles, hipersexualizadas o frías, como señalan los estereotipos que les atribuyen los medios de comunicación o algunos informes más o menos detallados. El estereotipo de "más crueles" que los hombres, derivado en parte de sus mayores condenas, hay que revisarlo ya que podría ocurrir que la mayor cuantía de sus condenas se debiera en parte a la aplicación de los estereotipos tradicionales en el funcionamiento de la justicia, que consideró de mayor gravedad sus delitos precisamente por el hecho de ser mujeres.

Por otra parte la masculinización de los grupos armados puede ser también el origen de ciertos comportamientos exagerados de las mujeres, explicados como una imitación de los aspectos más burdos de la masculinidad tendentes a demostrar su adecuación y valía en el seno de las organizaciones armadas. Eso no quiere decir que en algún momento no vivieran un importante conflicto para aceptar los métodos de lucha e intentaran resolverlo estando "lo más lejos posible de la sangre y la muerte", lo cual les "alivia problemas de conciencia”. La evaluación de la experiencia de implicación activa en la lucha armada es una cuestión de sumo interés y está impregnada de una lógica social tan evidente que desmiente las razones estereotípicas que suelen aparecer en los medios de comunicación e incluso en los informes más o menos profesionales. El sentido de las acciones de estas mujeres es puramente social impregnado de razones interpersonales e históricas, políticas e ideológicas como suelen ser las de los actores políticos masculinos. No parecen ser victimas, atrapadas en medio del conflicto como les señala la Comisión de la Verdad, son claramente agentes conscientes del lugar en el que estuvieron y del papel que jugaron, es decir del hueco de significado histórico que llenaron con sus vidas, eslabón de una cadena que unos/as han iniciado y otros/as van a continuar en el futuro.

El grupo en el que estuvieron, tanto el grupo político anterior a su entrada en los movimientos, como el grupo armado al que pertenecieron, y el grupo en el que se insertaron una vez que fueron encarceladas, es un elemento vital y básico en la reconstrucción del sentido de sus acciones y en la reconstrucción de sus fracturas identitarias.

Como es habitual en la comisión de actos de violencia sobre todo si esta es política, la implicación en actos que conllevan consecuencias graves para si mismos o los otros no parece especialmente traumática, si cuenta con una justificación 
suficientemente convincente que nunca es elaborada únicamente por el individuo sino que se construye en el marco de unas premisas o discursos sobre la realidad que se vive que son establecidos por el grupo e referencia y las ideologías que este defiende. En este marco las muertes acusadas por la acción política serán concebidas como eslabones necesarios de la acción, dificultades u obstáculos que habrá que superar. Desde el comienzo, sabían que no sería fácil, por ello, intentan asumirlos con "naturalidad". Los actos cobran "sentido" lo cual no es sinónimo de justificación o razón moral. Cuando decimos que tiene sentido queremos decir que es justificada en el marco de la interacción concreta, de la situación, "entendida como una estrategia útil y en cierto modo entendible o aceptable por parte de los agresores" (Fernández Villanueva, 2007:166).

En especial son las mujeres integrantes del PCP-SL las que tienen un discurso del Partido como "salvador", no sólo para su vida, sino para el mundo en general. El convencimiento de la lógica y la necesidad de implicarse en la violencia se impone. Como consecuencia, podemos afirmar que, a pesar de los indudables conflictos identitarios que vivieron, incluido el de utilizar la violencia, la mayoría se sintieron cumplidoras de un papel en la historia de su grupo y por ello, coherentes y justas. Algunas incluso satisfechas por el papel desempeñado ejerciendo la violencia. La “democratización de la violencia" que se está produciendo en los últimos tiempos y no la psicologización de los comportamientos, es el marco más explicativo de este fenómeno de creciente importancia y visibilidad. Las mujeres peruanas son un ejemplo más que refuerza las razones estructurales y psicosociales de la implicación de las mujeres como agentes de violencia política en sus diferentes tipos. 


\section{BIBLIOGRAFÍA}

- Alcoff, L. (1988): "Cultural feminism versus post-structuralism: the identity crisis in feminist theory". En Signs, vol. 13, n. 3, pp. 405-436.

- Arnoletto, J. (2007): "Curso de Teoría Política" [en línea] Disponible en: http://www.eumed.net/libros/2007b/300/indice.htm [12/12/2010].

- Balbuena, L. (2007): "Violencia y agencia femenina: ¿puede el terror empoderar a la mujer?”. En M. Barrig (ed.) Fronteras interiores. Identidad, diferencia y protagonismo de las mujeres. Lima: IEP.

- Blair Trujillo, E. y Londoño, L. (2003): "Experiencias de guerra desde la voz de las mujeres”. En Nómadas, nº 19. Bogotá: DIUC/Universidad Central, pp. 106-115.

- Bourdieu, P. (1998): Sobre la televisión. Barcelona: Anagrama. . (2007): La dominación masculina. Barcelona: Anagrama.

- Coral, I. (1999): “Las mujeres en la guerra: impacto y respuestas”. En S. Stern (ed.): Los senderos insólitos del Perú: guerra y sociedad 1980-1995. Lima: IEP/UNSCH, pp. 338-397.

- Caro, R. (2006): "Ser mujer, joven y senderista: género y pánico moral en las percepciones de Sendero Luminoso", Revista Allpanchis, nº. 67, Cusco, pp. 125-156.

- CVR - Comisión de la Verdad y Reconciliación del Perú (2003): Informe Final. Lima: CVR.

- Fernández Villanueva, C. (2007): "Violencia y agresiones: pinceladas para una nueva perspectiva psicosocial interaccionista". En J. Romay (ed.): Perspectivas y retrospectivas de la Psicología Social en los albores del siglo XXI. Madrid: Biblioteca Nueva, pp.163-170

- Henríquez, N. (2006): Cuestiones de género y poder en el conflicto armado en el Perú. Lima: CONCYTEC.

- Ibarra Melo, M. E. (2007): Transformaciones identitarias de las mujeres como resultado de su participación política en las guerrillas y en las acciones colectivas por la paz en Colombia. Madrid: UCM.

- Jiménez, B. (2000): Inicio, desarrollo y ocaso del terrorismo en el Perú. El abc de Sendero Luminoso y el MRTA ampliado y comentado. Lima: Servicios gráficos SANKI.

- Kirk, R. (1993): Grabado en piedra. Las mujeres de Sendero Luminoso. Lima: IEP.

- Lagroye, J. (1993): Sociología política. Buenos Aires: Fondo de Cultura Económica.

- Lahire, B. (2007): "Infancia y adolescencia: de los tiempos de socialización sometidos a constricciones múltiples". Revista de Antropología Social, nº. 16, Madrid: UCM, pp. 203-216. 
- Lázaro, J. (1998): "Women and political violence in contemporary Peru”. En M. J. Diamond (ed.): Women and revolution: global expressions. Netherlands: Kluwer Academic Publishers, pp. 233-247.

- Luna, L. (2002): “La historia feminista del género y la cuestión del sujeto". En Boletín Americanista, $\mathrm{n}^{\circ} .52$ [en línea] Disponible en: http://www.lolagluna.com/publicaciones/ articulos/Lahistoria.pdf [15/12/2010].

- Panos Institute. (1995). Armas para luchar, brazos para proteger: Las mujeres hablan de la guerra. Barcelona: Icaria.

- Pedersen, D. (1999): “El impacto de la pobreza, el racismo y la violencia política sobre la salud de los pueblos indoamericanos". En M. Bronfman y R. Castro (eds.): Salud, cambio social y políticas: perspectivas desde América Latina. México: EDAMEX, Instituto Nacional de Salud Pública, pp. 163-184.

- Rénique, J. L. (2003): La Voluntad Encarcelada. Las "luminosas trincheras de combate" de Sendero Luminoso del Perú. Lima: IEP.

- Vázquez, N.; Ibáñez, C. y Murguialday, C. (1996): Mujeres-montaña. Vivencias de guerrilleras y colaboradoras del FMLN. Madrid: Horas y Horas.

- Vega-Centeno, I. (2000): ¿Imaginario femenino? Cultura, Historia, Política y Poder. Lima: Escuela para el Desarrollo, EPD. 